\title{
MENYIMAK PENOMENA PEMANASAN GLOBAL/PERUBAHAN IKLIM (La-Nina), ALIH FUNGSI LAHAN DAN MITIGASI KERUSAKAN LINGKUNGAN DI PULAU BALI
}

\section{INVESTIGATING THE GLOBAL WARMING/CLIMATE CHANGE (LA-NINA) PHENOMENA, LAND USE CHANGE AND ENVIRONMENTAL DEGRADATION MITIGATION ON BALI ISLAND}

\author{
I Wayan Kasa ${ }^{1}$, Ida Bagus Wayan Gunam ${ }^{2}$ \\ ${ }^{1}$ Faculty of Science, Udayana University, Bukit Jimbaran Campus, Denpasar, Bali, Phone: \\ 03612166767 \\ ${ }^{2}$ Faculty of Agricultural Technology, Udayana University, Bukit Jimbaran Campus, \\ Denpasar, Bali \\ Email: iwkasa@yahoo.com
}

\begin{abstract}
ABSTRAK
Sampai saat ini (bulan Agustus 2016) walaupun tergolong wilayah musim panas (AprilOktober), Bali masih turun hujan (penomena La-Nina). Metode yang dipakai dalam pengamatan ini yaitu dengan mengumpulkan data primer (langsung kelapangan) dan data skunder (informasi dari media cetak). Hasil pengamatan penomena La-Nina menunjukkan bahwa, komoditi perkebunan seperti produksi kopi masa panennya menjadi lebih pendek, buah mengalami kerontokan sebelum masak, sehingga produksi mengalami penurunan. Kenyataan ini bisa dilihat pada petani kopi didesa Sepang, kecamatan Busungbiu, Kabupaten Buleleng. Selain itu, beberapa pantai di Bali permukaan air laut mengalami kenaikan cukup signifikan yang terjadi dipantai Lepang, kecamatan Banjarangkan, Kabupaten Klungkung. Air laut naik kedarat menggenangi areal persawahan seluas kurang lebih lima hektar. Lebih dari pada itu, penomena La-Nina juga bisa disaksikan dengan hilangnya habitat kepiting purba dipantai pulau Nusa Penida dan naik kedarat menempati sebuah Gua Giri Putri. Alih fungsi areal persawahan menjadi rumah tinggal penduduk terus belangsung. Namun demikian usaha mitigasi kerusakan lingkungan dari pemerintah sebagai penyeimbang tetap dilakukan seperti penguatan peran dari kebun raya Eka Karya Bedugul sebagai ruang terbuka hijau dan pusat kegiatan penelitian.
\end{abstract}

Kata kunci: pemanasan global, La-Nina, alih fungsi lahan, adaptasi, mitigasi, Bali

\begin{abstract}
ABTRACT
Up to now Bali island still suffering from light to heavy rainfall (August 2016), eventhough it must be hot season as usual (April to October). Such situation is recognised as La-Nina phenomenon. Methode empolyed in this study is collecting primary (direct field check) and scondary data (literature study). Results showed that, the La-Nina phenomena most affected coffee plantation farmers in the village of Sepang, district of Busungbiu, Buleleng regency. The coffee fruit fall out from stem branch prior to harvest time and becoming black in colour. In addition, some coffee fruit skin are white in colour in comparison to red to black during normal hot season. Land use change could also be seen over Bali. Increase sea level on some beaches are also another disaster around Bali. Such accidence was significantly happened on the beach of Lepang village, district of Banjarangkan, Klungkung regency. It was found that such increases puddling area of more or less five hectare of paddy rice field on that area. The global warming/climate change phenomenon also cause habitat loss of specific ancient crab who live in Nusa Penida beach and move into the Giri Putri holy cave to survive. However, the only government do to compromise and mitigate such abnormal environmental degradation
\end{abstract}


would be by strengthening the essen of the Eka Karya botanical garden of Bedugul as an open green field area for refreshing.

Keywords: global warming/, la-nina, land use change, adaptation, mitigation, Bali

\section{PENDAHULUAN}

Sebagai negara kepulauan,
Indonesia dibelah oleh katulistiwa (equator-cross country) dan terletak diantara dua samudra dan dua benua sehingga mempunyai keaneka ragaman curah hujan, temperatur, kelembaban dan arah angin (Aldrian, et al., 2007). Semua unsur tersebut membentuk satuan iklim khas Indonesia yang terdiri dari musim hujan dan kemarau. Namun situasi iklim Indonesia tidak bisa terlepas dari pengaruh iklim global, sehingga dalam perjalanan tidak jarang terjadi anomali seperti El-Nino, La-Nina, angin puyuh, putting beliung dll. Belum lagi kalau bicara pengaruh pemanasan global/perubahan iklim (global warming/climate change) yang sebagian besar disebabkan oleh ulah manusia (anthropogenic factor) selain faktor alam (natural factor). Selain itu, penomena alih fungsi lahan (land use change) sebagai suatu peristiwa yang patut menjadi perhatian umat manusia tidak bisa dilihat sebelah mata. Dengan kata lain umat manusia diplanet bumi dihadapkan kepada ancaman serius yang harus diusahakan jalan keluarnya. Kalau tidak maka cepat atau lambat, manusia akan dihadapkan pada kemungkinan bencana yang mengancam kelangsungan hidup kedepan. Sebagai contoh, negara Indonesia sebagai anggota masyarakat dunia telah berkomitmen menurunkan emisi gas rumah kaca (green house gases) $26-41 \%$ dari tingkat emisi Business as Usual pada tahun 2020 (Masripatin, 2011). Kebijakan ini tentu harus disertai dengan tanggung jawab besar bangsa ini, dari akar rumput (bottom up) sampai jajaran paling atas (top down). Beban yang dipikul oleh sektor kehutanan jelas sangat besar. Bali sebagai bagian integral Indonesia dan dunia tidak bisa dipisahkan dari seluruh peristiwa tersebut. Bencana demi bencana menghampiri Bali yang kecil terutama pengaruh turunnya hujan yang berkepanjangan yang dikenal sebagai penomena La-Nina. Belum lagi giliran bencana lain datang mengancam, seperti efek pemanasan global/perubahan iklim, dan maraknya alih fungsi lahan dengan segala akibat buruk menerpa pulau kecil ini. Bulan Juli dan Agustus yang biasa dikenal sebagai puncak musim kemarau, nyatanya masih ditandai guyuran hujan menyebabkan gangguan panen buah lokal dibeberapa tempat di Bali. Berdasarkan kenyataan dan penomena tersebut maka pengamatan ini perlu dilakukan sehingga kedepan bisa diantisipasi dengan sederet rencana aksi (action plan) bersekala daerah dan nasional.

\section{METODE PENGAMATAN}

Pengamatan mempergunakan data primer dengan pengecekan langsung kelapangan, selain pengumpulan data sekunder dari sumber media cetak dan elektronik.

\section{HASIL DAN PEMBAHASAN}

Penomena

pemanasan global/perubahan iklim/La-Nina. Data mengenai hal ini disajikan pada Gambar 1. Pengamatan dilakukan bulan Juli sampai Agustus 2016. Hasil pengamatan 
menunjukkan akibat cuaca tidak bersahabat maka buah kopi siap panen rontok yang terjadi didesa Sepang, kecamatan Busungbiu, kabupaten Buleleng. Tidak hanya itu, akibat gangguan cuaca juga mengakibatkan masa panen mundur dari biasanya. Selanjutnya didapatkan produksi dan kualitas kopi turun drastis dibandingkan musim panen tahun sebelumnya yaitu tahun 2015. Ditemukan juga bahwa buah kopi yang mengalami kerontokan warnanya masih hijau sampai hitam sebagai pertanda buah tidak sehat yang berujung pada penurunan kualitas buah. Hasil penghitungan petani menunjukkan bahwa setiap hektar tanaman jumlah kerotokan mencapai lima persen. Info lain dari petani bahwa dalam keadaan cuaca normal Juli-Agustus biasanya sudah selesai panen selanjutnya hanya tinggal proses pengeringan saja. Proses pengeringan juga menjadi terhambat akibat intensitas sinar matahari tidak penuh karena tutupan awan dan hujan. Gejala ini juga diketemukan dikabupaten Tabanan dan Bangli, Bali. Penomena ini kemungkinan disebabkan oleh pengaruh pemanasan global/perubahan iklim yang berujung pada terjadinya La-Nina yaitu bertambah panjangnya musim hujan sebagai akibat curah hujan berlebihan. Secara normal musim hujan berlangsung bulan Oktober sampai April.

Kenyataan ditahun 2016 menunjukkan bahwa sampai bulan Agustus cuaca masih berawan yang diikuti turun hujan. Bahkan ramalan dari Badan Meteorologi, Klimatologi dan Geofifisika (BMKG) Bali menyatakan bahwa cuaca berawan dan hujan masih bisa tejadi sampai bulan September 2016 (Gambar 2). Selain itu hal ini kemungkinan disebabkan juga oleh penomina La-Nina, musim hujan yang berkepanjangan. Kenyataan ini didukung oleh pendapat Damanik (2016) yang menyatakan bahwa dibulan Agustus 2016 Indonesia sedang dilanda kemarau basah. Situasi ini disebabkan oleh suhu muka laut (SST) diwilayah perairan barat Aceh mengalami kenaikan berkisar antara 29,55$29,65{ }^{\circ} \mathrm{C}$ dan anomali positif antara 0,75 $0,80^{\circ} \mathrm{C}$ yang berarti bawha pasokan uap air diwilayah perairan barat Aceh tambah besar sebagai akibat naiknya sea surface temperature (SST). Ditambah lagi adanya tekanan rendah disamudra Hindia sebelah barat Sumatra sehingga terjadi pasokan uap air dan terbentuknya awan hujan cumulusnimbus yang berpotensi hujan sedang sampai lebat pada malam hingga dini hari.

Penomena kemarau basah ini kemungkinan juga bisa disebabkan oleh anomali cuaca yang disebut Indian Ocean Dipole (IOD). Pendapat ini dibenarkan oleh (Luo et al., 2010) yang menyatakan bahwa pola hujan di Indonesia yang beragam sangat berhubungan dan erat kaitannya dengan $\mathrm{La}$ Nina dan IOD yang berpengaruh besar terhadap lingkungan dan masyarakat (environment and social impacts). Khusus mengenai pola hujan dalam kaitannya dengan IOD dinyatakan bahwa dalam situasi seperti ini disebut sebagai IOD negatif artinya bahwa see surface temperature (SST) di Samudra Hindia Barat lebih dingin dari SST rata-rata (SST klimatologis), sementara SST di Samudra Hindia Tenggara (terutama diperairan Indonesia) lebih hangat. Kondisi tersebut mengakibatkan adanya aliran udara basah dari arah barat ketimur yang mengkibatkan turun hujan (Saji et al., 1999; Saji and Yamagata, 2003b; Bannu et al., 2005 and As-syakur et al., 2014). 
Pristiwa naiknya air laut di Pantai Lepang, Kecamatan Banjarangkan, Kabupaten Klungkung. Data mengenai hal ini disajikan pada Gambar 3. Hasil pengamatan menunjukkan bahwa cuaca tidak bersahabat disertai hujan turun terjadi antara tanggal 1 dan 3 Agustus 2016. Akibat dari kondisi ini, air laut naik sejauh kurang lebih 300 meter dari bibir pantai menuju daratan. Keadaan ini berakibat terendamnya areal persawahan seluas ratarata 5 hektar, sehingga berujung pada gagal panen. Walaupun bulan Agustus merupakan bulan puncak musim panas, namun kenyataan menunjukkan guyuran hujan masih berlangsung hingga mengakibatkan ombak besar dan naiknya permukaan air laut. Kejadian ini merupakan anomali keadaan cuaca untuk tahun 2016 untuk Bali yang tidak terjadi pada tahun keadaan normal. Hal ini kemungkinan disebabkan oleh pengaruh lain dari La-Nina dan IOD tersebut (Bannu et al., 2005; Assyakur et al. 2014 dan Damanik,2016) yang ditandai oleh turun hujan dimusim kering yang mengakibatkan volume air laut bertambah sehingga mengakibatkan naiknya permukaan air laut sampai menggenangi daratan.
Kepiting bakau (Scylla Serrata). Sebagai rangkaian naiknya permukaan air laut dipantai Lepang, kabupaten Klungkung, ada lagi peristiwa lain. Dipulau Nusa Penida yang masih wilayah kabupaten sama, terlihat sejumlah kepiting bakau (Scylla Serrata) hijrah kesebuah gua kuno tidak jauh dari pantai dengan kumpulan hutan bakau. Kasus perpindahan satwa ini kemungkinan disebabkan oleh habitat kepiting tersebut mengalami gangguan (penebangan bakau oleh penduduk, kematian yang disebakan oleh beberapa faktor dll) sehingga tidak nyaman dan pindah kehabitat yang lebih cocok yaitu Gua Giri Putri. Kemungkinan lain terjadi alih fungsi lahan hutan bakau menjadi areal tambak atau peruntukan lain seperti perumahan, hotel, jalan dan infrastruktur yang lain. Hasil pengamatan alih fungsi lahan juga terdapat dibeberapa tempat di Bali, misalnya kota Denpasar (Gambar 5). Dengan kata lain terjadinya kemajuan dibidang sosioekonomi masyarakat (escalating human socioeconomic activities) selama dua ratus tahun terakhir merupakan salah satu penyebab alih fungsi, sesuai dengan pendapat Brinson and Malvarez (2002).

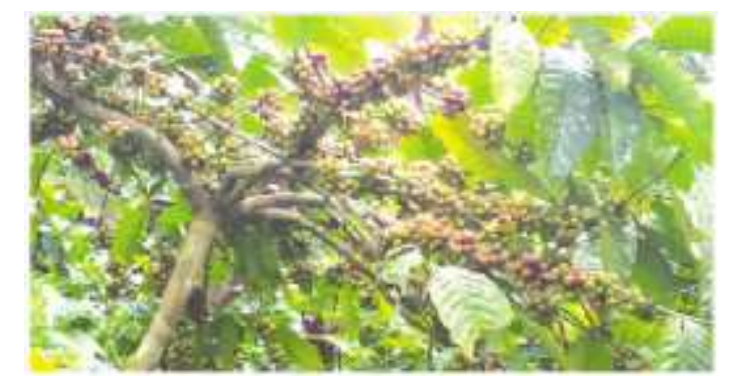

Gambar 1: $\quad$ Buah kopi jenis robusta perkebunan petani didesa Sepang, Kecamatan Busungbiu, Kabupaten Buleleng, Bali. Buah mengalami kerontokan akibat curah hujan berlebihan (phenomena LaNina). (Sumber: Bali Post 18 Juli 2016). 


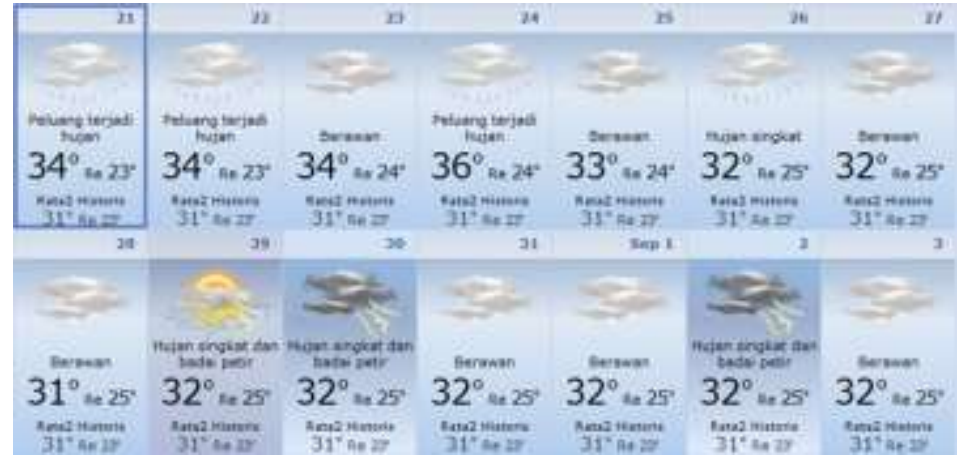

Gambar 2: $\quad$ Kondisi cuaca Bali akhir Agustus sampai permulaan September 2016 yang masih diwarnai oleh keadaan berawan dan hujan. (Sumber: BMKG Bali 10 Agustus 2016).

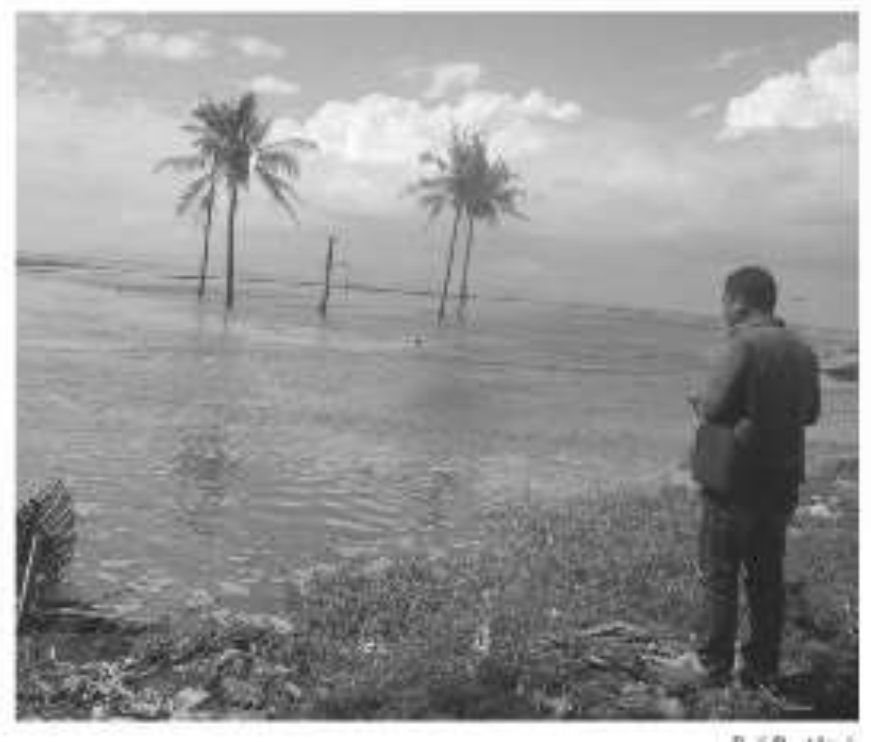

Gambar 3: $\quad$ Permukaan air laut naik dipantai Lepang, Kecamatan Banjarangkan, Kabupaten Klungkung, Bali menggenangi sawah petani sebagai phenomena pemanasan global /perubahan iklim. (Sumber: Bali Post 4 Agustus 2016)
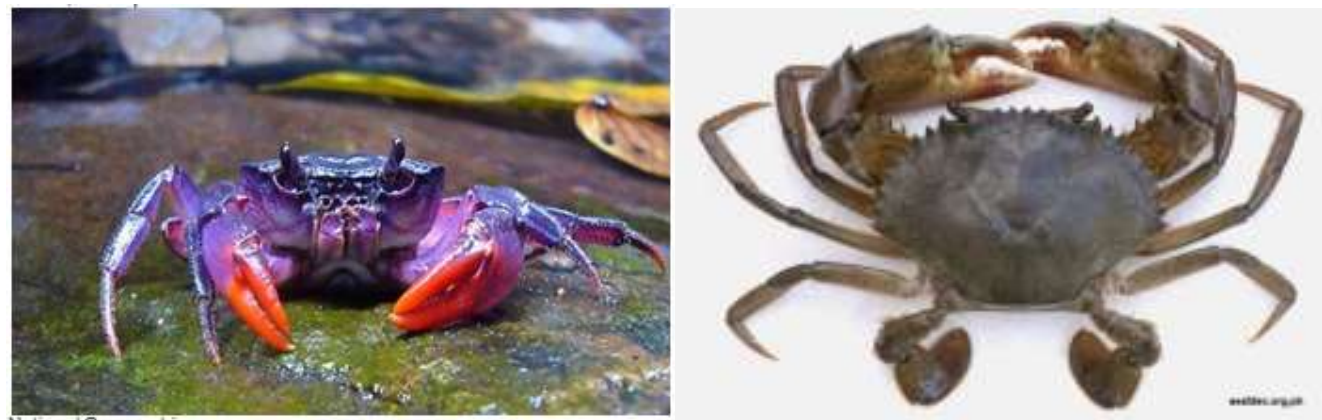

Gambar 4:(kiri): Kepiting biru (Callinectes sapidus) yang muncul akibat pengaruh pemanasan global dan (kanan) kepiting bakau (Scylla Serrata) 


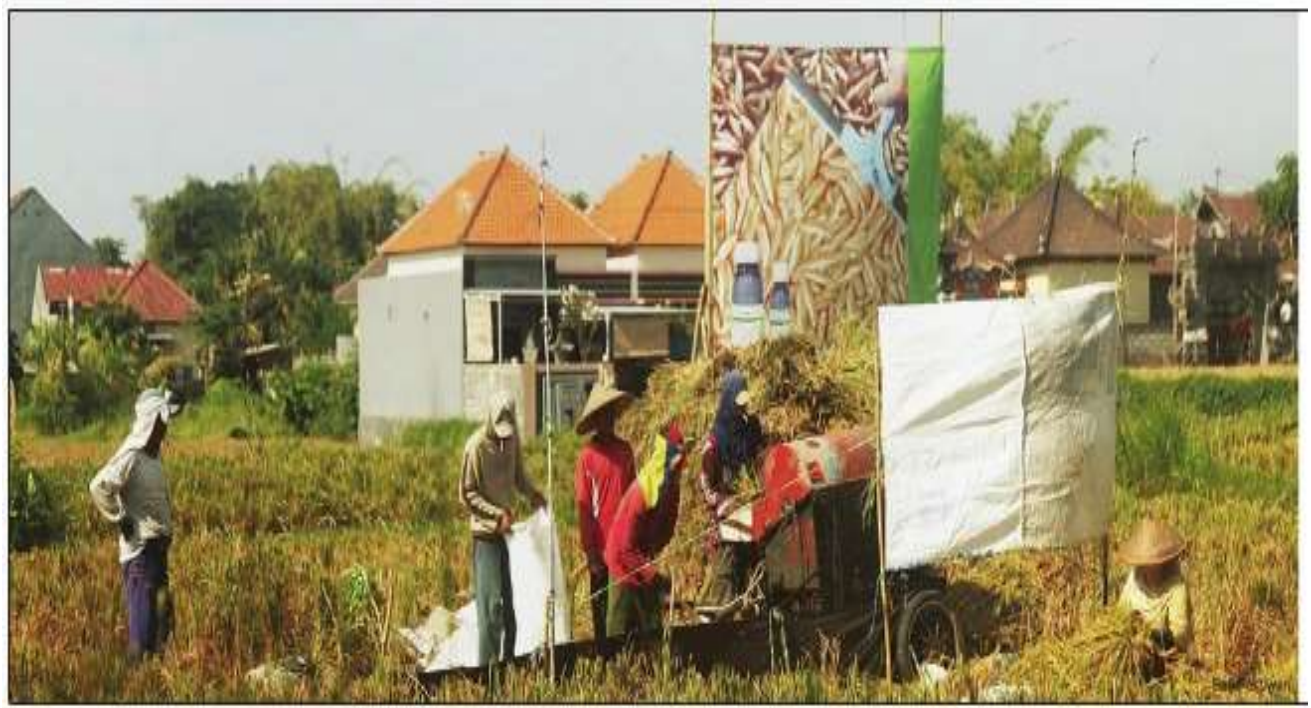

Gambar 5: $\quad$ Alih fungsi lahan pertanian menjadi pemukiman penduduk akibat pesatnya pertambahan jumlah penduduk sekitar kota Denpasar, Bali. (Sumber: Bali Post 8 Agustus 2016).

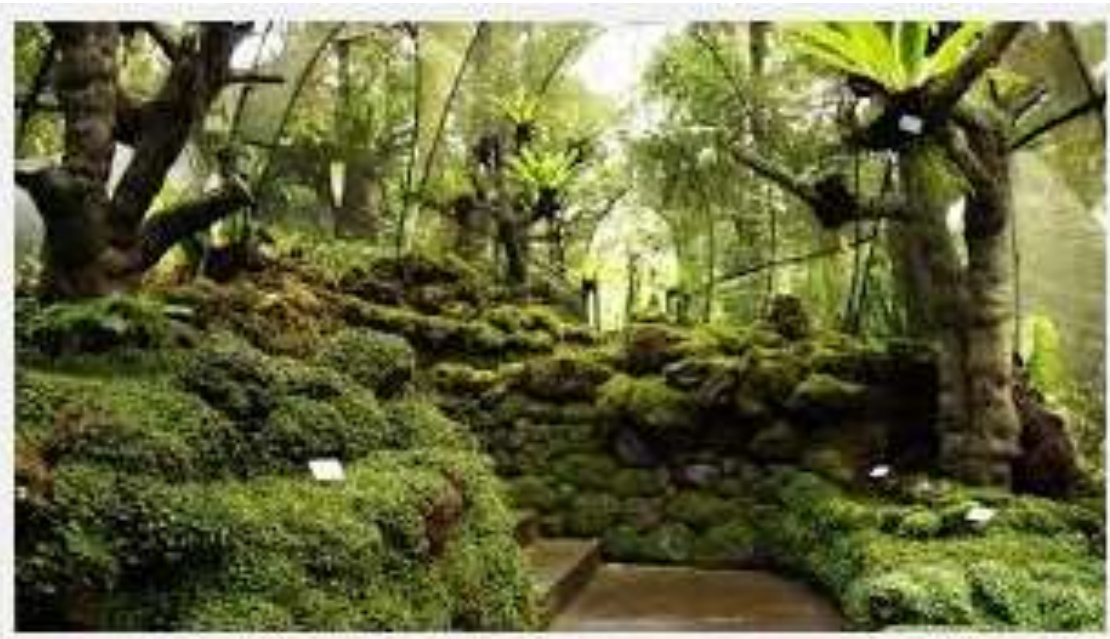

Gambar 6: Kebun Raya Eka Karya Bedugul, Bali 


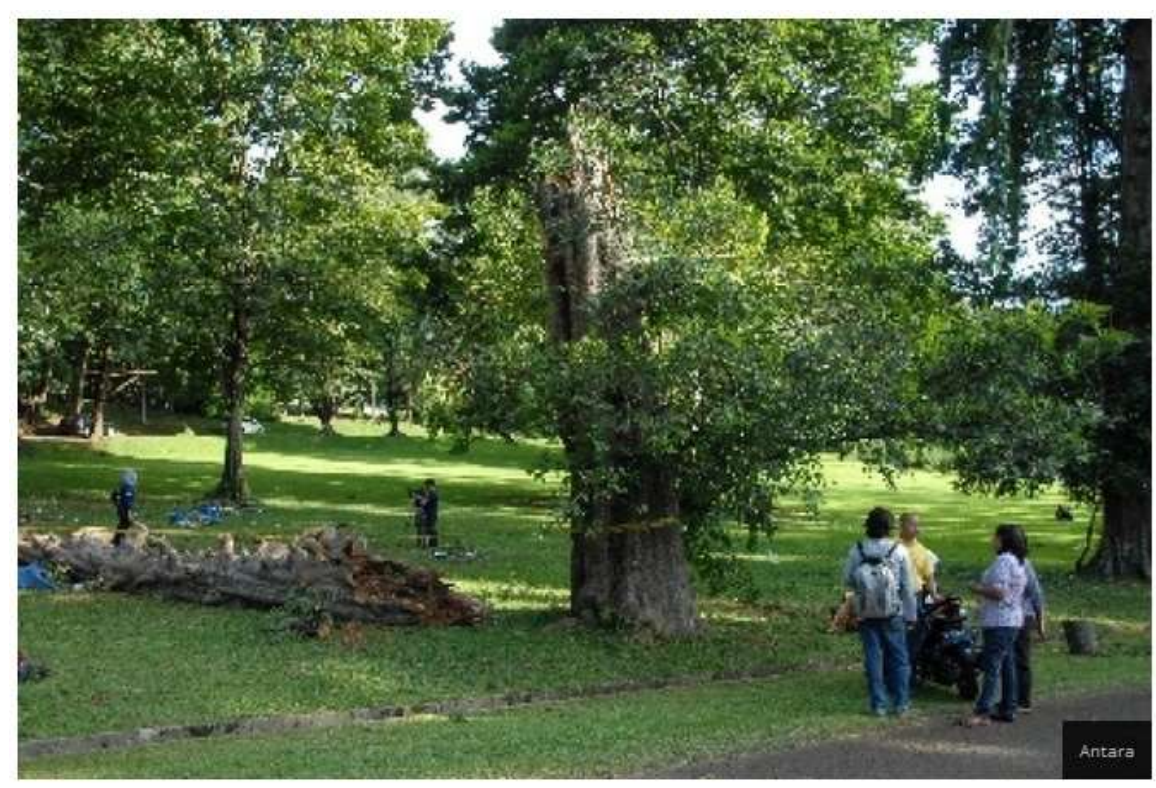

Gambar 7: Kebun Raya Pilan Gianyar, Bali

Usaha adaptasi dan mitigasi kerusakan lingkungan. Data mengenai usaha pemerintah bersama rakyat dalam rangka adaptasi dan mitigasi kerusakan lingkungan disajikan pada Tabel 1, Gambar 6 dan Gambar 7. Kebun Raya Bedugul memiliki areal taman dan hutan lindung dengan luas sekitar 157,5 hektar dengan koleksi tanaman yang mencapai kira-kira 16.000 tanaman yang terdiri dari 1.500 jenis, 320 marga, dan 155 suku tumbuhan. Dapat dibagi menjadi beberapa kelompok baik itu tanaman untuk dilindungi maupun tanaman liar yang merupakan tanaman hias, tanaman buah, tanaman obat, tanaman untuk bahan-bahan upacara, dsb. Terdapat juga taman anggrek / orchid park dengan berbagai koleksinya (Gambar 6). Selain itu Pemerintah Kabupaten Gianyar, Bali berencana membangun kebun raya tematik di Kawasan Hutan Adat Pilan, Desa Kerta, Payangan. Ini akan menjadi kebun raya ke30 di Indonesia (Gambar 7) dengan luas 10 ha. Ditambah lagi usaha pemerintah bersama rakyat mempertahankan luasan hutan rakyat yang kini mencapai 24.549 ha
(Tabel 1). Semua usaha ini bertujuan untuk menjaga dan mempertahankan lingkungan agar tetap lestari (maintain and sustainable development) dalam arti seluas-luasnya dalam mengemban prinsip REDD++ (Stacy and Marvin 2002: Barron and McDermott, 2015). 
Tabel 1: $\quad$ Luas lahan (hutan) dikabupaten di Bali

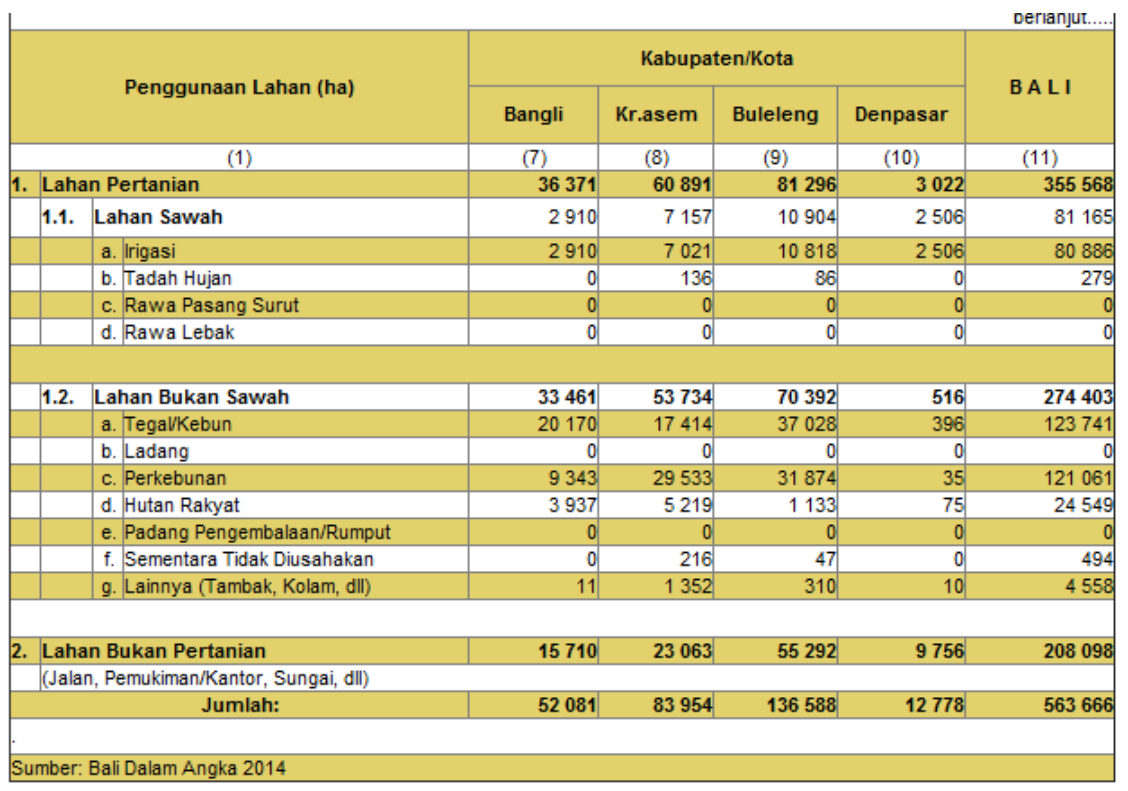

\section{KESIMPULAN}

Dari uraian tersebut dapat disimpulkan bahwa pengaruh pemanasan global/perubahan iklim yang terimplementasi dalam phenomena $L a$ Nina jelas terlihat pengaruhnya dibeberapa daerah di Bali. Namun demikian pemerintah bersama rakyat tetap melakukan rencana aksi (action plan) baik berupa rencana aksi daerah (RAD) atau rencana aksi nasional (RAN).

\section{DAFTAR PUSTAKA}

Aldrian E, Gates LD, Widodo FH. 2007. Seasonal variability of Indonesian rainfall in ECHAM4 simulations and in the reanalyses: the role of ENSO. Theor. Appl. Climatol. 87: 41-59.

As-syakur AR, Sandi Adnyana IW, Mahendra MS, Arthana IW, Merit IN, Kasa IW, Ekayanti NW, Nuarsa IW, Sunarta IN. 2014. Observation of spatial patterns on the rainfall response to ENSO and IOD over Indonesia using TRMM
Multisatellite Precipitation Analysis (TMPA)

Bannu KH, Takeuchi N, Suriamihardja DA. 2005. Impacts of the sea surface temperature anomaly in the Pacific and Indian Oceans on the Indonesian climate. Paper presented at the 11th CEReS International Symposium on Remote Sensing, 13-14 December 2005, Chiba University, Chiba, Japan.

Barron DP, McDermott CL. 2015. Environmental Impacts in 'Reducing Emissions from Deforestation and Degradation. Journal of Environmental Policy and Planning, 17 (2): 277-293

Brinson MM, Malvarez AI. 2002. Temperate freshwater wetlands: types, status, and threats. Environmental Conservation, 29: 115-133. 
Damanik RA. 2016. Kemarau Basah Menghampiri Indonesia. Bali Post 1 Agustus 2016, halaman 6.

Ignatio MP, Jose NP, Ignatio G. Magaly K. 2010. Detecting drought induced environmental changes in a Mediterranean wetland by remote sensing. Applied Geography, 30: 254-262.

Masripatin N. (2011). Mengelola Peran Kehutanan dalam Target Pengurangan Emisi 26\%. Pusat standarisasi dan lingkungan kementrian kehutanan. Prosiding, hal. Iii. Kata Pengantar.

Saji NH, Goswami BN, Vinayachandran PN, Yamagata T. 1999. A dipole mode in the tropical Indian Ocean. Nature 401: 360-363.

Saji NH, Yamagata T. 2003b. Possible impacts of Indian Ocean Dipole mode events on global climate. Clim. Res. 25: 151-169.

Stacy LO, Marvin EB. 2002, Satellite remote sensing of wetlands. Wetlands Ecology and Management, 10: 381- 402. 